\title{
Diabetes em Movimento: a Portuguese web- based platform to support exercise prescription by medical doctors
}

\author{
Romeu Mendes, ${ }^{1,2,3}$ Nelson Sousa, ${ }^{3,4}$ Marcos Agostinho, ${ }^{5,6}$ Victor Machado Reis, ${ }^{3,4}$ \\ José Luís Themudo-Barata ${ }^{7,8}$
}

'Public Health Unit, ACES Douro I - Marão e Douro Norte, Northern Region Health Administration, Vila Real, Portugal

2EPI Unit - Instituto de Saúde Pública, Universidade do Porto, Porto, Portugal

${ }^{3}$ University of Trás-os-Montes e Alto Douro, Vila Real, Portugal

${ }^{4}$ Research Center in Sports Sciences, Health Sciences and Human Development, Vila Real, Portugal

${ }^{5}$ CUF Torres Vedras Hospital, Torres Vedras, Portugal ${ }^{6}$ USF Santa Cruz, ACES Oeste Sul, Lisbon and Tagus Valley Region Health Administration, Torres Vedras, Portugal ${ }^{7}$ Cova da Beira Hospital Centre, Covilhã, Portugal

${ }^{8}$ Faculty of Health Sciences, University of Beira Interior, Covilhã, Portugal

\section{Correspondence to}

Romeu Mendes, Unidade de Saúde Pública, ACES Douro

I - Marão e Douro Norte, Administração Regional de Saúde do Norte IP, Rua Miguel Torga, 12 F, 5000-524 Vila Real, Portugal;

romeuduartemendes@gmail. com

Accepted 29 May 2017 Published Online First 20 June 2017

Check for updates

To cite: Mendes $\mathrm{R}$, Sousa N, Agostinho M, et al. Br I Sports Med 2018:52:540-541.

\section{NAME OF THE MOBILE APPLICATION \\ Diabetes em Movimento - exercise prescription platform.}

\section{CATEGORY OF THE MOBILE APPLICATION \\ Health and fitness.}

\section{PLATFORM}

Web-based, available at http://www.diabetesemmovimento.com.

\section{COST}

Free of charge, although restricted to medical doctors registered in Portuguese Medical Association.

\section{ABOUT THE APP}

Medical doctors can build a home-based exercise programme for patients with type 2 diabetes (T2D) by choosing exercises from a database of images and editing the basic exercise prescription parameters (weekly frequency, duration, sets, repetitions and intensity) of each exercise (figure 1). The exercise database has three aerobic exercises (walking-based), 32 resistance exercises (performed only with a chair, a pair of $0.5 \mathrm{~L}$ water bottles filled with sand and a gymnastics ball) and nine flexibility exercises. Videos of all the resistance exercises are also available and can be seen by medical doctors and patients at the office or at home. Several recommendations can be selected and incorporated into the exercise programme according to the diabetes comorbidities of each patient in order to prevent exercise-related adverse events, ${ }^{1}$ such as assessing glycaemia before and after exercise, observing the feet and the socks before and after the exercise routine, using comfortable shoes, drinking water during exercise (minimum $0.5 \mathrm{~L}$ per hour), having something to eat if necessary, no breath-holding during exercises (Valsalva manoeuvre), avoiding head contact or shaking, avoiding walking on hard floors like asphalt, preferring clay, grass or tartan, and not using public swimming pools if foot ulcers or wounds are present. Exercise intensity is prescribed according to Borg's rate of perceived exertion scale (6-20 points), and the scale is also incorporated into the exercise programme. Three levels of exercise intensity are available for prescription: light (10-11 points), moderate (12-13 points) and vigorous (14-15 points). There are also three default exercise programmes that can quickly be selected with different exercise volumes (basic, intermediate and advanced). It is also possible to fill out the patient's name and choose the duration of the programme (from 1 to 6 months). The final exercise programme (which includes images of all selected exercises) can be printed and given to the patient in a handout format or sent via email in PDF file format.

\section{USE IN CLINICAL PRACTICE}

Physical activity (PA) is one of the major risk factors for non-communicable chronic diseases (NCDs). Medical doctors play an important role in promoting PA and reducing sedentary behaviour to a broad segment of the population. ${ }^{2} \mathrm{~T} 2 \mathrm{D}$ is one of the NCDs that benefit the most from regular exercise. Most of this population is sedentary, although PA is included in all international strategies to control T2D. ${ }^{3}$ Age, anthropometric profile and diabetes comorbidities contribute to exercise prescription difficulty. Although originally created for a T2D context, this tool can be used to promote exercise for the management of any NCD and for the elderly population. This platform was developed under Diabetes em Movimento, a Portuguese community-based intervention programme designed to promote PA and lifestyle changes for patients with T2D. ${ }^{4}$ Web-based tools and technologies can greatly contribute to enhance PA participation, and home-based exercise programmes with low cost and high applicability exercise strategies can be prescribed in clinical settings with the support of this platform.

\section{PROS}

- Free of charge

- Web-based platform available in any mobile phone, tablet or personal computer

- Simple design and easy to navigate

- Low cost and high applicability exercise strategies with the use of everyday objects such as chairs and bottles of water

- Videos demonstrating the exercises

- Exercise intensity control and recommendations for exercise-related adverse events

- Exercise programme can be printed and given to the patient in a handout format or sent via email in PDF file format

- No advertisements.

\section{CONS}

- Restricted to medical doctors registered in Portuguese Medical Association 


\section{DPABEIES}

PLATAFORMA DE PRESCRICEOL

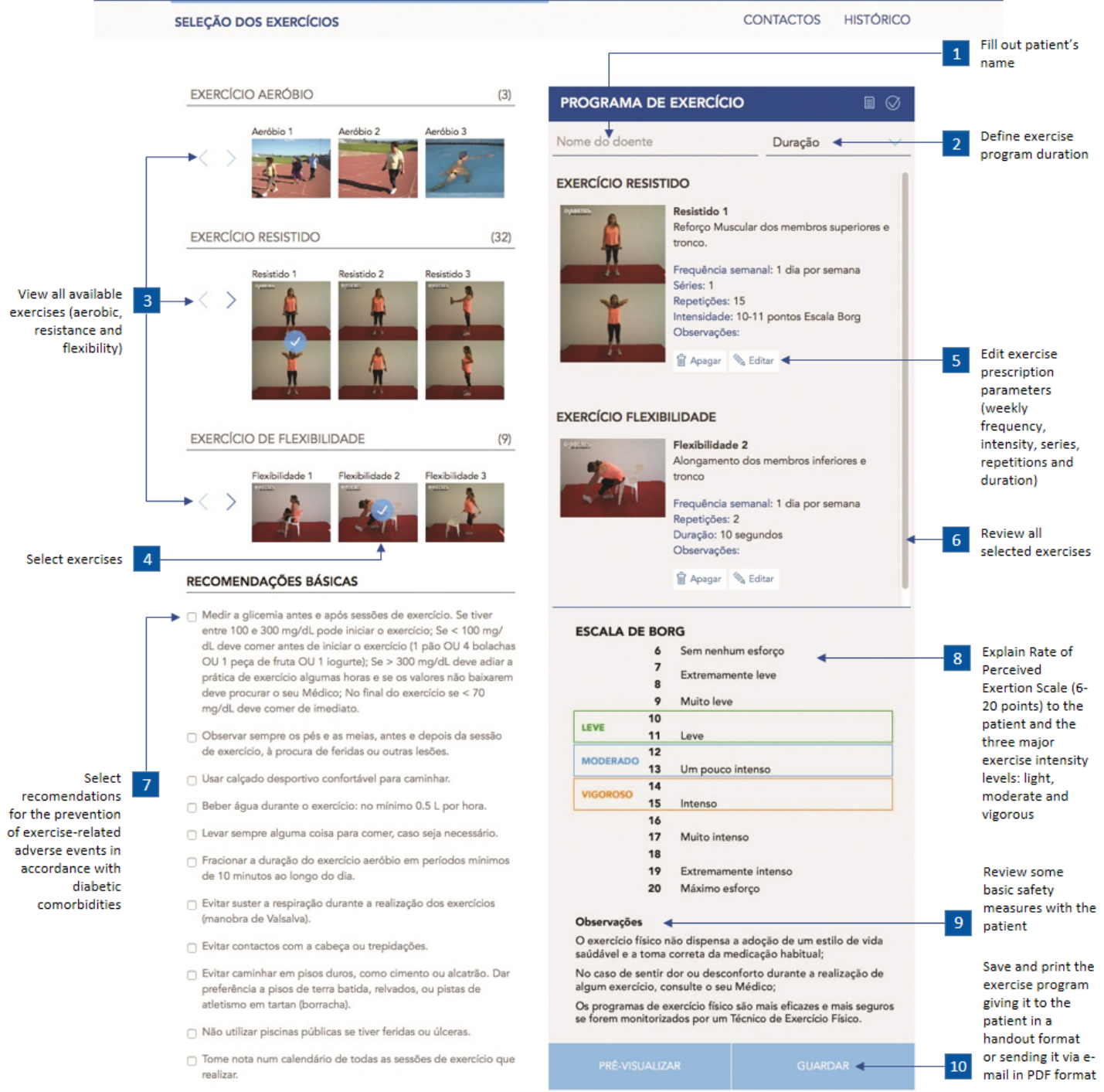

Figure 1 General vision of Diabetes em Movimento—exercise prescription platform.

- Only in Portuguese language

- Internet access is always required.

Contributors All authors were involved in the web-based platform design. RM and JLTB wrote the paper. NS, MA and VMR reviewed and approved the paper.

Competing interests None declared.

Patient consent Obtained from patients.

Provenance and peer review Not commissioned; externally peer reviewed.

(C) Article author(s) (or their employer(s) unless otherwise stated in the text of the article) 2018. All rights reserved. No commercial use is permitted unless otherwise expressly granted.

\section{REFERENCES}

1 Mendes R, Sousa N, Reis VM, et al. Prevention of exercise-related injuries and adverse events in patients with type 2 diabetes. Postgrad Med J 2013;89:715-21.

2 Thornton JS, Frémont P, Khan K, et al. Physical activity prescription: a critical opportunity to address a modifiable risk factor for the prevention and management of chronic disease: a position statement by the canadian Academy of Sport and Exercise Medicine. Br J Sports Med 2016;50:1109-14.

3 Mendes R, Sousa N, Almeida A, et al. Exercise prescription for patients with type 2 diabetes-a synthesis of international recommendations: narrative review. Br J Sports Med 2016;50:1379-81.

4 Mendes R, Sousa N, Almeida A, et al. Lifestyle intervention in type 2 diabetes: Diabetes em Movimento ${ }^{\circ}$ community-based exercise program. Eur J Pub Health 2015;5(Suppl 3): 100 . 


\section{BISM Diabetes em Movimento: a Portuguese web-based platform to support exercise prescription by medical doctors}

Romeu Mendes, Nelson Sousa, Marcos Agostinho, Victor Machado Reis and José Luís Themudo-Barata

Br J Sports Med2018 52: 540-541 originally published online June 20, 2017

doi: 10.1136/bjsports-2017-097758

Updated information and services can be found at:

http://bjsm.bmj.com/content/52/8/540

\section{These include:}

References This article cites 4 articles, 3 of which you can access for free at: http://bjsm.bmj.com/content/52/8/540\#ref-list-1

Email alerting Receive free email alerts when new articles cite this article. Sign up in the service box at the top right corner of the online article.

\section{Notes}

To request permissions go to:

http://group.bmj.com/group/rights-licensing/permissions

To order reprints go to:

http://journals.bmj.com/cgi/reprintform

To subscribe to BMJ go to:

http://group.bmj.com/subscribe/ 